\title{
Comparison of the Effectiveness of Monitoring Cisplatin-Induced Ototoxicity with Extended High-Frequency Pure-Tone Audiometry or Distortion-Product Otoacoustic Emission
}

\author{
Kwang Kyu Yu ${ }^{1}$, Chi Ho Choi ${ }^{1}$, Yong-Hwi An ${ }^{1}$, Min Young Kwak ${ }^{1}$, \\ Soo Jung Gong ${ }^{2}$, Sang Won Yoon ${ }^{1}$, and Hyun Joon Shim ${ }^{1}$ \\ ${ }^{1}$ Departments of Otolaryngology, ${ }^{2}$ Internal Medicine, Eulji Medical Center, Eulji University School of Medicine, Seoul, Korea
}

$\begin{array}{ll}\text { Received } & \text { April 2, 2014 } \\ \text { Revised } & \text { July 1, 2014 } \\ \text { Accepted } & \text { July 10, 2014 }\end{array}$

Address for correspondence

Hyun Joon Shim, MD, PhD

Department of Otolaryngology,

Eulji Medical Center,

Eulji University School of Medicine,

68 Hangeulbiseok-ro, Nowon-gu,

Seoul 139-872, Korea

Tel $+82-2-970-8276$

Fax $+82-2-970-8275$

E-mail eardoc11@naver.com
Background and Objectives: To compare the effectiveness of monitoring cisplatin-induced ototoxicity in adult patients using extended high-frequency pure-tone audiometry (EHF-PTA) or distortion-product otoacoustic emission (DP-OAE) and to evaluate the concurrence of ototoxicity and nephrotoxicity in cisplatin-treated patients. Subjects and Methods: EHF-PTA was measured at frequencies of $0.25,0.5,1,2,3,4,6,8,9,11.2,12.5,14,16,18$, and $20 \mathrm{kHz}$ and DP-OAE at frequencies of $0.5,0.75,1,1.5,2,3,4,6$, and $8 \mathrm{kHz}$ in cisplatin-treated patients $(n=10)$. Baseline evaluations were made immediately before chemotherapy and additional tests were performed before each of six cycles of cisplatin treatment. Laboratory tests to monitor nephrotoxicity were included before every cycle of chemotherapy. Results: Four of 10 patients showed threshold changes on EHF-PTA. Five of 10 patients showed reductions in DP-OAE, but one was a false-positive result. The results of EHF-PTA and DP-OAE were consistent in two patients. Only one patient displayed nephrotoxicity on laboratory tests after the third cycle. Conclusions: In our study, the incidence rate of cisplatin-induced ototoxicity was $40 \%$ with EHF-PTA or DP-OAE. Although both EHF-PTA and DP-OAE showed the same sensitivity in detecting ototoxicity, they did not produce the same results in all patients. These two hearing tests could be used to complement one another. Clinicians should use both tests simultaneously in every cycle of chemotherapy to ensure the detection of ototoxicity.

Korean J Audiol 2014;18(2):58-68

KEY WORDS: Cisplatin · Ototoxicity · Otoacoustic emission · Pure-tone audiometry.

\section{Introduction}

The first-generation platinum drug cisplatin is widely and frequently used for the treatment of various cancers. It is an effective drug against many kinds of cancer but also has many associated adverse effects, including ototoxicity, nausea, vomiting, nephrotoxicity, bone-marrow suppression, and hepatotoxicity. ${ }^{1)}$ The ototoxicity of cisplatin is known to correlate with its cumulative dose. However, hearing loss (HL) after cisplat-

This is an Open Access article distributed under the terms of the Creative Commons Attribution Non-Commercial License (http://creativecommons. org/licenses/by-nc/3.0/) which permits unrestricted non-commercial use, distribution, and reproduction in any medium, provided the original work is properly cited. in treatment is difficult to predict based only on the cumulative dose because there is significant individual variability in susceptibility to ototoxicity. ${ }^{2)}$ However, cisplatin-induced ototoxic damage is usually considered irreversible once it has occurred. ${ }^{3)}$ These facts justify the mandatory monitoring of ototoxicity to ensure its early detection.

Ototoxic effects often first appear at frequencies $>8 \mathrm{kHz}$. Numerous previous studies have demonstrated the value of extended high-frequency pure-tone audiometry (EHF-PTA) for the early detection of cisplatin-induced ototoxicity (Cis-OT), because Cis-OT begins in the most basal region of the cochlea. ${ }^{3)}$ Distortion-product otoacoustic emission (DP-OAE) potentially reflects subclinical cochlear damage because DP-OAE am- 
plitude reduction arises from outer-hair-cell damage, which occurs before inner-hair-cell damage. Some clinicians advocate the use of DP-OAE because this test is not affected by the patient's age or any deterioration in the patient's general condition caused by chemotherapy.

The first aim of our study was to investigate which of these tests is the more sensitive method for detecting Cis-OT. We performed both EHF-PTA and DP-OAE in every cisplatintreated patient and compared the ototoxicity detection rates of the two tests. Our second aim was to assess the concurrence of ototoxicity and nephrotoxicity in cisplatin-treated patients. Serum blood urea nitrogen (BUN) and serum creatinine (Cr) levels and the glomerular filtration rate (GFR) were measured to detect nephrotoxic complications.

\section{Subjects and Methods}

This study was performed with the approval of the Institutional Review Board of Eulji General Hospital and all the participants gave their informed consent. A prospective study was carried out in 17 patients who were undergoing chemotherapy that included cisplatin from May 2011 to August 2013. Seven of these patients discontinued their follow-up voluntarily or dropped out of the study. The data for the 10 patients who completed the tests throughout all their cycles of chemotherapy were collected.

All 10 patients were diagnosed with cancer by pathological evaluation, including two with lung cancer, two with gastric cancer, four with gynecological malignancies, one with gall bladder cancer, and one with common bile duct cancer. Each patient received several (2-6) cycles of cisplatin and i.v. dose calculated from the body surface area of each patient. The hearing levels of the patients were evaluated with EHF-PTA and DP-OAE. The baseline evaluation was made immediately before chemotherapy commenced and additional tests were performed immediately before each cycle of cisplatin treatment, and one month after the end of treatment. None of our patients had received any ototoxic drug other than cisplatin.

EHF-PTA was measured at frequencies of 0.25, 0.5, 1, 2, 3, $4,8,9,11.2,12.5,14,16,18$, and $20 \mathrm{kHz}$ using an AC40 clinical audiometer (Interacoustics, Assens, Denmark). All the patients were tested in both ears, and the pure-tone audiometric thresholds, in decibels hearing level (dB HL), were measured through air and bone conduction. The presence or absence of a change in the hearing threshold was based on published clinical guidelines [American Speech-Language-Hearing Association (ASHA) 1994] and included: 1) $\geq 20 \mathrm{~dB}$ change at any one test frequency; 2) $\geq 10 \mathrm{~dB}$ change at any two consecutive test frequencies; or 3 ) loss of response at three consecutive test frequencies at which responses were previously obtained (ASHA 1994). ${ }^{4)}$

Navigator PRO (Bio-logic Systems Corp., Mundelein, IL, USA) was used to assess DP-OAE. The sound stimulus for DP-OAE consisted of two simultaneous permanent pure tones at different frequencies $\left(f_{1} / f_{2}\right.$ ratio $\left.=1.22\right)$ at $60 \mathrm{~dB}$ SPL $(\mathrm{L} 1>$ L2), and DP-OAE was measured at eight different frequencies: $0.5,0.75,1,1.5,2,3,4,6$, and $8 \mathrm{kHz}$. Change in DP-OAE was defined as a reduction in the signal-to-noise ratio (SNR) at $f_{2}$ frequencies below $1 \mathrm{kHz}$, which is the difference between the amplitude of DP-OAE and the noise floor at each test $f_{2}$ frequency. A reduction in SNR greater than $14 \mathrm{~dB}$ was regarded as significant. At $f_{2}$ frequencies above $1 \mathrm{kHz}$, a reduction in SNR greater than $7 \mathrm{~dB}$ was considered a significant clinical change. ${ }^{5,6)}$

Serum BUN, serum Cr, and GFR were tested to monitor nephrotoxicity. Blood samples were taken immediately before each cycle of chemotherapy.

Statistical analyses were performed with the SPSS statistical software package (SPSS, version 15.0 for Windows; SPSS Inc., Chicago, IL, USA). The results of the blood tests before each cycle were compared using multivariate analysis of variance. The correlations between the cumulative dose of cisplatin and the risk factors for developing ototoxicity were calculated using Pearson's correlation analysis. Differences were considered statistically significant at a $p$ value of $<0.05$.

\section{Results}

Six of the 10 study subjects were men and four were women. The mean age of the group was $58.7 \pm 10.3$ years (range, 40-71 years). No child subject was included. The mean initial dose of cisplatin was $114.0 \pm 40.3 \mathrm{mg} / \mathrm{m}^{2}$ (range, $40-160$ $\mathrm{mg} / \mathrm{m}^{2}$ ) and the mean total infused dose was $610.0 \pm 286.6$ $\mathrm{mg} / \mathrm{m}^{2}$ (range, $80-960 \mathrm{mg} / \mathrm{m}^{2}$ ). Five patients received six cycles of chemotherapy, two of them received five cycles, another two received four cycles, and one of them received two cycles (mean, five cycles; range, 2-6 cycles)(Table 1). One patient (subject 10) had mixed-type HL on the right side and a ventilation tube was inserted before the study. No other patient complained of HL, tinnitus, or aural fullness before therapy. Four of the 10 patients [subjects 1, 3, 5, and 10 (left ear only), seven of 20 ears] revealed threshold changes on EHF-PTA (Table 2). Five ears showed threshold changes below $8 \mathrm{kHz}$ (one ear at $3 \mathrm{kHz}$, two ears at $4 \mathrm{kHz}$, and another two ears at $8 \mathrm{kHz}$ ), and another two ears showed changes at frequencies over $9 \mathrm{kHz}$ (one ear at $9 \mathrm{kHz}$ and the other ear at $10 \mathrm{kHz}$ ). One patient (subject 10) with unilateral HL before treatment showed a threshold change at $8 \mathrm{kHz}$ on the healthy 
Table 1. Summary of ototoxicity and nephrotoxicity after cisplatin-based chemotherapy

\begin{tabular}{|c|c|c|c|c|c|c|c|c|c|c|}
\hline & \multirow[b]{2}{*}{ Age } & \multirow[b]{2}{*}{ Sex } & \multirow[b]{2}{*}{$\begin{array}{c}\text { Initial } \\
\text { dose } \\
\left(\mathrm{mg} / \mathrm{m}^{2}\right)\end{array}$} & \multirow[b]{2}{*}{$\begin{array}{c}\text { Number } \\
\text { of } \\
\text { cycles }\end{array}$} & \multirow[b]{2}{*}{ Side } & \multicolumn{2}{|c|}{ PTA } & \multicolumn{2}{|c|}{ DP-OAE } & \multirow[b]{2}{*}{$\begin{array}{c}\text { Nephrologic } \\
\text { laboratory } \\
\text { changes }\end{array}$} \\
\hline & & & & & & $\begin{array}{c}\text { Lowest } \\
\text { frequency } \\
\text { that showed } \\
\text { threshold } \\
\text { change }(\mathrm{kHz})\end{array}$ & $\begin{array}{l}\text { Hearing loss } \\
\text { time } \\
\text { (cumulative } \\
\text { dose; } \mathrm{mg} / \mathrm{m}^{2} \text { ) }\end{array}$ & $\begin{array}{l}\text { Frequencies } \\
\text { that showed } \\
\text { DP-OAE value } \\
\text { change }(\mathrm{kHz})\end{array}$ & $\begin{array}{c}\text { Hearing loss } \\
\text { time } \\
\text { (cumulative } \\
\text { dose; } \mathrm{mg} / \mathrm{m}^{2} \text { ) }\end{array}$ & \\
\hline \multirow[t]{2}{*}{ Subject 1} & 58 & $\mathrm{~F}$ & 160 & 6 & $R$ & 10 & $\begin{array}{l}\text { After } 3 \text { rd cycle } \\
\quad(480)\end{array}$ & 6 & $\begin{array}{l}\text { After 3rd cycle } \\
(480)\end{array}$ & Yes \\
\hline & & & & & L & 9 & $\begin{array}{l}\text { After } 3 \text { rd cycle } \\
\quad(480)\end{array}$ & $4,6,8$ & $\begin{array}{l}\text { After 3rd cycle } \\
\quad(480)\end{array}$ & \\
\hline \multirow[t]{2}{*}{ Subject 2} & 64 & $M$ & 105 & 4 & $R$ & - & - & - & - & No \\
\hline & & & & & L & - & - & - & - & \\
\hline \multirow[t]{2}{*}{ Subject 3} & 53 & $\mathrm{~F}$ & 130 & 6 & $R$ & 3 & $\begin{array}{l}\text { After 6th cycle } \\
(780)\end{array}$ & $4,6,8$ & $\begin{array}{l}\text { After 6th cycle } \\
(780)\end{array}$ & No \\
\hline & & & & & L & 4 & $\begin{array}{l}\text { After 6th cycle } \\
(780)\end{array}$ & $4,6,8$ & $\begin{array}{l}\text { After 6th cycle } \\
(780)\end{array}$ & \\
\hline \multirow[t]{2}{*}{ Subject 4} & 65 & M & 130 & 6 & $R$ & - & - & - & - & No \\
\hline & & & & & L & - & - & - & - & \\
\hline \multirow[t]{2}{*}{ Subject 5} & 40 & $\mathrm{~F}$ & 130 & 6 & $R$ & 4 & $\begin{array}{l}\text { After 6th cycle } \\
(780)\end{array}$ & 8 & $\begin{array}{l}\text { After 6th cycle } \\
(780)\end{array}$ & No \\
\hline & & & & & L & 8 & $\begin{array}{l}\text { After 6th cycle } \\
(780)\end{array}$ & - & - & \\
\hline \multirow[t]{2}{*}{ Subject 6} & 44 & M & 140 & 5 & $R$ & - & - & - & - & No \\
\hline & & & & & L & - & - & - & - & \\
\hline \multirow[t]{2}{*}{ Subject 7} & 62 & M & 40 & 2 & $R$ & - & - & - & - & No \\
\hline & & & & & L & - & - & - & - & \\
\hline \multirow[t]{2}{*}{ Subject 8} & 71 & $\mathrm{~F}$ & 140 & 5 & $R$ & - & - & - & - & No \\
\hline & & & & & L & - & - & $2^{*}$ & $\begin{array}{l}\text { After } 5 \text { th cycle* } \\
(700)\end{array}$ & \\
\hline \multirow[t]{2}{*}{ Subject 9} & 70 & $M$ & 45 & 4 & $R$ & - & - & - & - & No \\
\hline & & & & & L & - & - & - & - & \\
\hline \multirow[t]{2}{*}{ Subject $10^{\dagger}$} & 60 & $\mathrm{~F}$ & 120 & 6 & $R$ & - & - & 3 & $\begin{array}{l}\text { After 4th cycle } \\
(480)\end{array}$ & No \\
\hline & & & & & L & 8 & $\begin{array}{l}\text { After } 4 \text { th cycle } \\
(480)\end{array}$ & 6 & $\begin{array}{l}\text { After 2nd cycle } \\
(240)\end{array}$ & \\
\hline
\end{tabular}

*false positive result, ${ }^{\dagger}$ subject 10 already had unilateral hearing loss on her right side. PTA: pure-tone audiometry, DP-OAE: distortionproduct otoacoustic emission

Table 2. Incidence of ototoxicity and nephrotoxicity after cisplatinbased chemotherapy

\begin{tabular}{lcc}
\hline & Patients $(\mathrm{n}=10)$ & Ears $(\mathrm{n}=20)$ \\
\hline PTA threshold change & $4(40 \%)$ & $7(35 \%)$ \\
DP-OAE value change & $4(40 \%)^{*}$ & $7(35 \%)^{*}$ \\
Subjective hearing change & $0(0 \%)$ & $0(0 \%)$ \\
BUN, Cr, GFR change & $1(10 \%)$ & - \\
\hline
\end{tabular}

*one ear showing a false-positive DP-OAE result was excluded. PTA: pure-tone audiometry, DP-OAE: distortion-product otoacoustic emission, BUN: blood urea nitrogen, Cr: creatinine, GFR: glomerular filtration rate

side only. Three ears (subjects 1 and 10) showed threshold changes during chemotherapy and another four ears (subjects 3 and 5) showed threshold changes after therapy ceased (Table 1, Fig. 1). To assess the overall changes in the hearing thresh- olds after chemotherapy, we plotted the average thresholds for all 10 patients at each frequency. There were no statistical differences in the hearing thresholds before and after treatment for either ear at any frequency measured (Fig. 2).

There was no significant correlation between the cumulative dose of cisplatin and the presence of hearing threshold changes on EHF-PTA $(p>0.05)$. There was also no significant correlation between the cumulative dose and the lowest frequency that showed hearing impairment $(p>0.05)$.

Five of the 10 patients (subjects 1, 3, 5, 8, and 10, eight of 20 ears) showed a reduction in DP-OAE, but one of the results (subject 8 ) was a false positive, in which the DP-OAE change only occurred at $2 \mathrm{kHz}$, whereas no change was detected with EHFPTA. The DP-OAE results were consistent with the EHF-PTA 
Yu KK, et al.

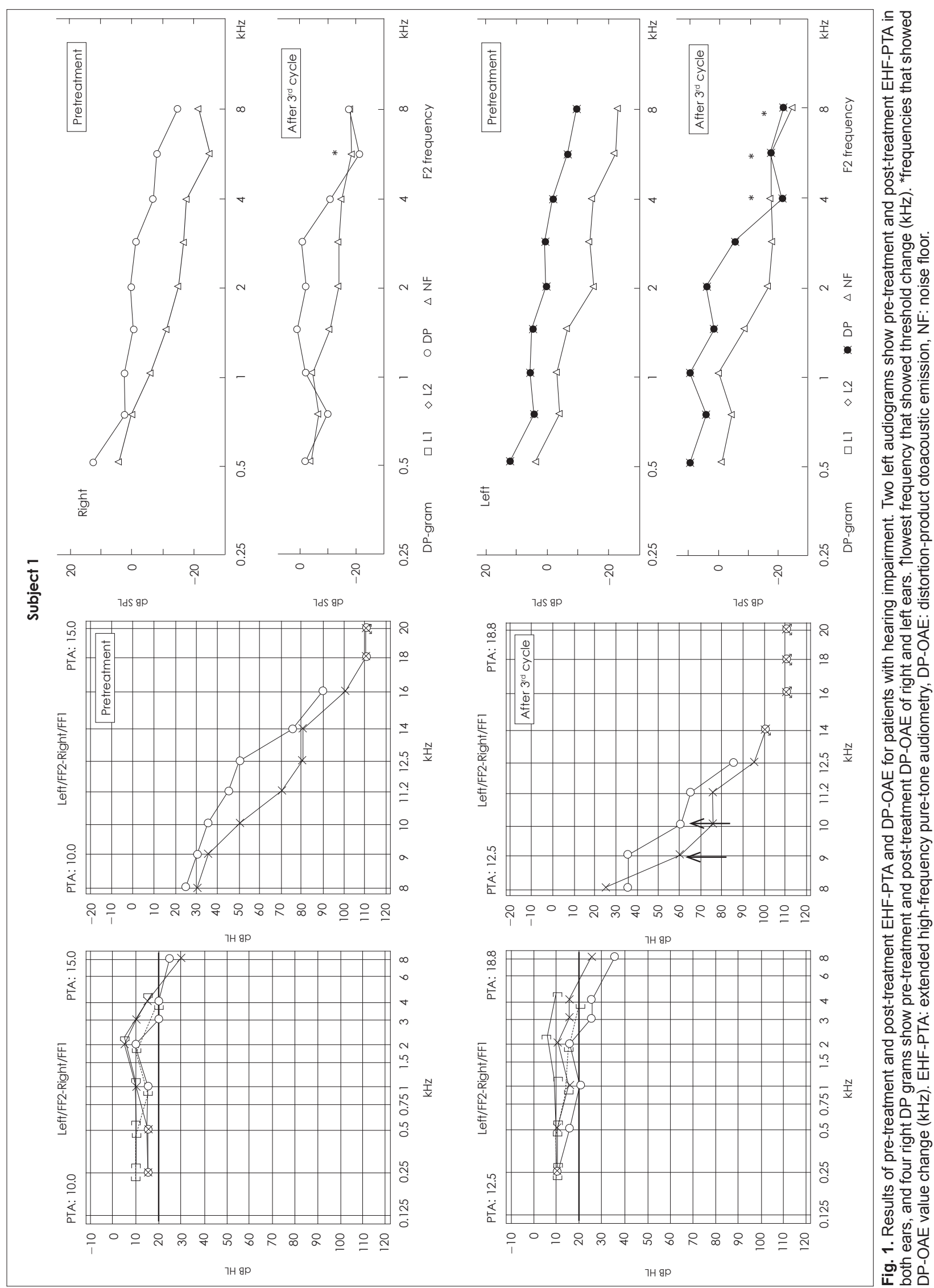




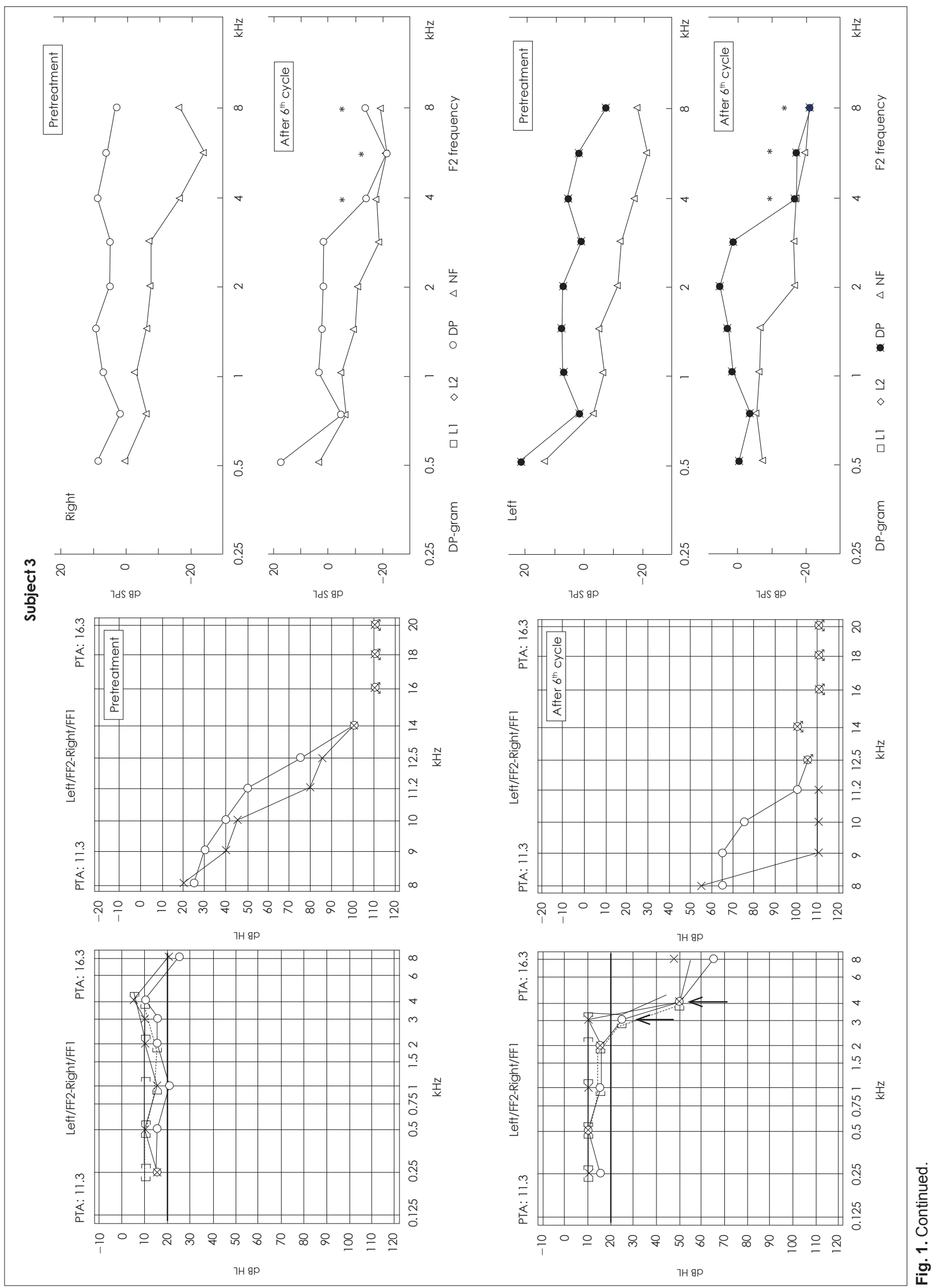


Yu KK, et al.

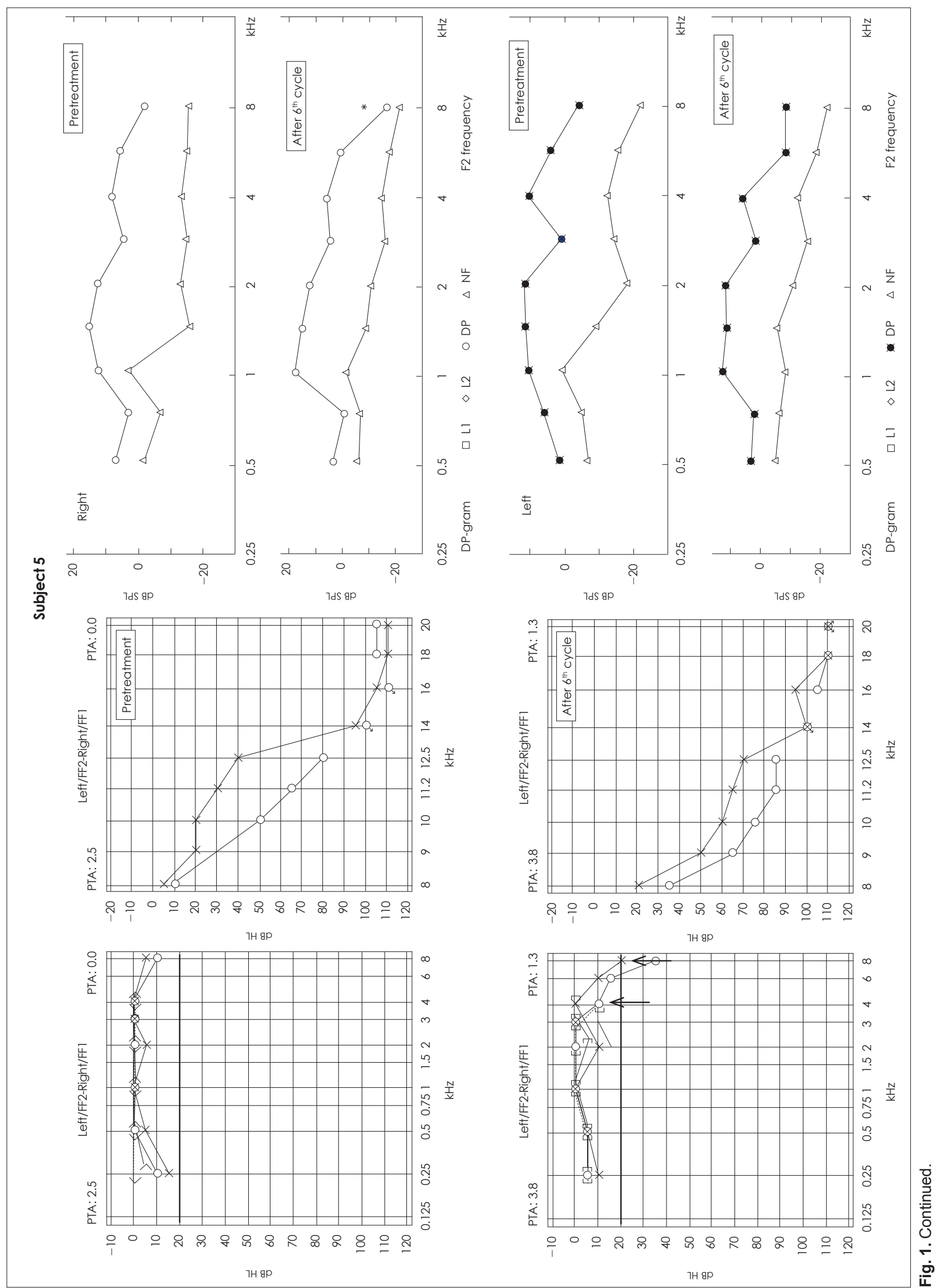




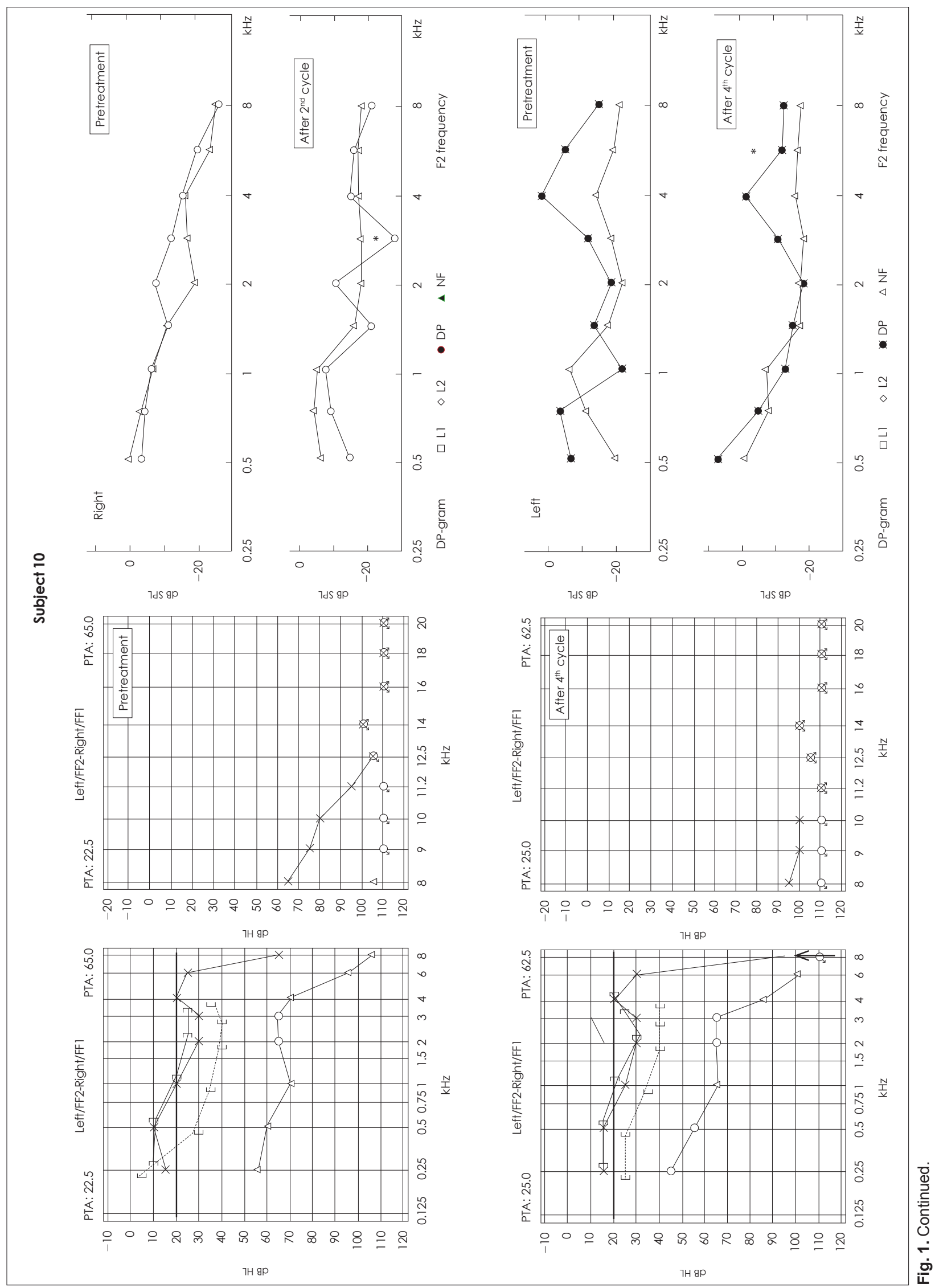




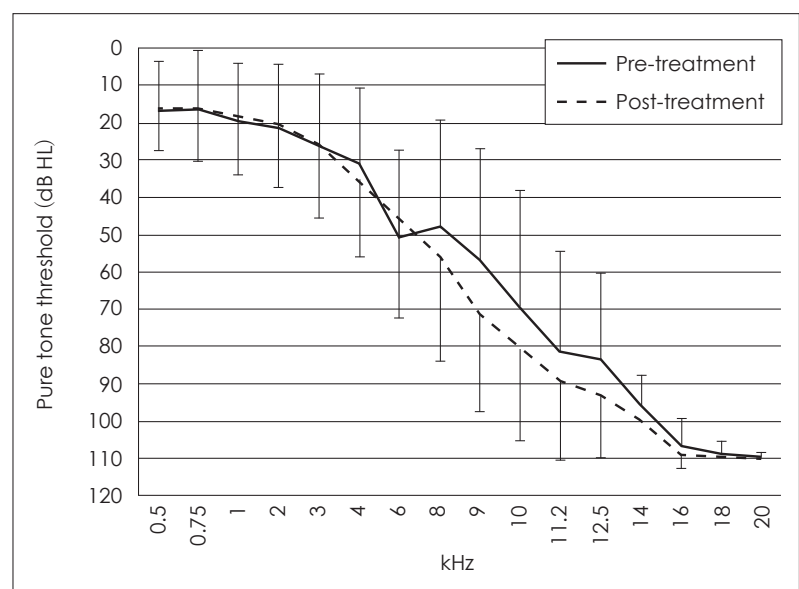

Fig. 2. Average pure tone threshold changes in each measured frequencies after cisplatin-based chemotherapy ( $n=20$ ears, right and left ears of 10 patients).

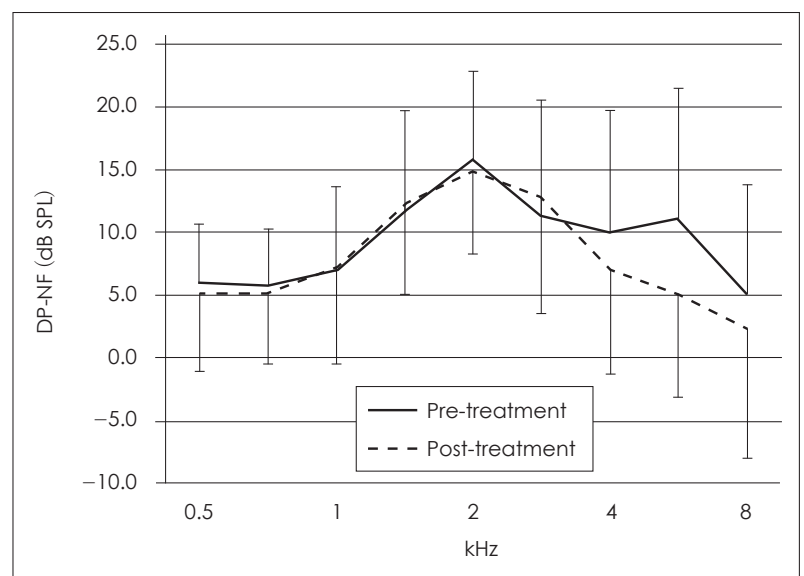

Fig. 3. Average DP-OAE changes in each measured frequencies after cisplatin-based chemotherapy $(n=20$ ears, right and left ears of 10 patients). DP-NF: distortion product-noise field, DP-OAE: distortion-product otoacoustic emission.

results in two patients (subjects 1 and 3 , four ears)(Table 1). Subject 5 showed bilateral HL on EHF-PTA, but the DP-OAE value only changed in the left ear. In contrast, the DP-OAE value changed on both sides in subject 10 , but the threshold change on EHF-PTA was only significant in the left ear. The time of detection of HL was the same with both tests, except for subject 10, in which DP-OAE detected HL earlier than EHFPTA. The sensitivity of EHF-PTA in detecting Cis-OT was $40 \%$ (four of 10 patients), as was the sensitivity of DP-OAE. DPOAE showed a false positive rate of $10 \%$ (Table 2). Average DP-OAE changes in each measured frequencies after cisplatin-based chemotherapy were plotted in Fig. 3. None of the subjects complained of their newly developed hearing disturbance or any otological problem during or after chemotherapy.

Only one patient (subject 1) displayed nephrotoxicity according to the laboratory tests, which occurred after the third cycle of chemotherapy, simultaneous with a hearing threshold change.
Both serum BUN and serum Cr were elevated and GFR was significantly reduced $(p<0.05)$.

\section{Discussion}

In the otological context, cisplatin is one of the most ototoxic drugs known. An animal experiment showed that cisplatin causes outer-hair-cell damage from the basal turn. ${ }^{7)}$ Initially, the first row of outer hair cells is affected, followed by the second and third rows, the inner hair cells, and finally the supporting cells. The progression of damage is typically from the high-frequency-coding cochlear base toward the apex..$^{711}$

In the present study, the incidence rate of Cis-OT was $40 \%$ (four of 10 patients) when detected with either EHF-PTA or DPOAE. In subject 5, DP-OAE failed to detect HL on one side. In subject 10, EHF-PTA failed to detect HL in one ear that originally already showed hearing impairment. The time of HL detection was the same in five ears with both tests, but was detected earlier with DP-OAE in subject 10. However, DP-OAE generated one false positive result. Because this subject presented with a level of reduction at $2 \mathrm{kHz}$ on DP-OAE only, although EHF-PTA detected no threshold change, it is reasonable to regard it as a false positive result. We could draw no conclusion from these data about which test is superior for the early detection of Cis-OT. The two tests seem to be mutually complementary. Therefore, clinicians should use both tests simultaneously in every cycle of chemotherapy to ensure the detection of ototoxicity. There are no standard criteria for defining changes in DP-OAE, and we used the criteria that have been used in many previous studies. ${ }^{5,6)}$ ASHA suggested the clinical criterion that DP-OAE changes should show a level reduction $\geq 4 \mathrm{~dB}$ or that a loss of response at two adjacent $f_{2}$ frequencies indicates a "reduction" on DP-OAE. However, when this criterion was applied in our study, only three of 20 ears $(15 \%)$ met the criterion (left ear of subject 1 , both ears of subject 3). This implies that the ASHA criterion is too strict for the early detection of ototoxicity.

The mean incidence of ototoxicity was $33 \%$ when patients received a single dose of $50 \mathrm{mg} / \mathrm{m}^{2}$ cisplatin. ${ }^{12)}$ Coradini, et al. ${ }^{13)}$ reported $52 \%$ bilateral HL in cisplatin-treated younger patients (median age, 12.3 years; median total dose of cisplatin, $406 \mathrm{mg} / \mathrm{m}^{2}$ ) using PTA, DP-OAE, and transient evoked otoacoustic emissions (TE-OAE). Another study using EHFPTA detected HL in 42 of 55 ears $(76.4 \%)$ after treatment. ${ }^{14)}$ In the study of Eiamprapai, et al., ${ }^{6)}$ the incidence rate of ototoxicity detected with DP-OAE was $77.3 \%$ in adult patients after a cumulative dose of cisplatin of $156.1 \pm 77.17 \mathrm{mg} / \mathrm{m}^{2}$. Another study reported that the incidence of ototoxicity was $81.3 \%$ in children (eight months to 20 years old) after a cumu- 
lative dose of cisplatin of $428 \pm 106 \mathrm{mg} / \mathrm{m}^{2}$, when detected with EHF-PTA, DP-OAE, and auditory brainstem response. ${ }^{15)}$ In the present study, all subjects received chemotherapy by own protocol of the department of oncology, and therapeutic doses of cisplatin were determined by the cell types of tumor and their body surfaces.

DP-OAE provides a noninvasive and objective measure of cochlear function, because DP-OAE is an acoustic response generated by the outer hair cells within the cochlea. In earlier studies published by Littman, et al. ${ }^{16)}$ and Ress, et al., ${ }^{17)} \mathrm{DP}-$ OAE was performed to determine the cochlear functional status after cisplatin treatment. Several studies reported that DPOAE was a more sensitive monitoring tool for detecting druginduced ototoxicity than conventional PTA or TE-OAE. ${ }^{18,19)}$ However, in this study, we could find the value of EHF-PTA in the monitoring ototoxicity. For example, bilateral hearing losses were detected at the frequencies over $9 \mathrm{kHz}$ of EHF-PTA in subject 1. Moreover, in subject 5, EHF-PTA detected ototoxicity in both ears whereas, DP-OAE failed to detect HL on either the two. Indeed, many previous studies have shown that EHF-PTA is a more sensitive tool for detecting ototoxicity than PTA at conventional frequencies, and have suggested that monitoring for ototoxicity must include a threshold evaluation of frequencies above $8 \mathrm{kHz}$. $^{14,20,21)}$

However, few studies have compared the sensitivity of EHFPTA and DP-OAE in monitoring Cis-OT. Reavis, et al. ${ }^{22)}$ reported that the DP-OAE hit rate was $78 \%$ in ears with hearing impairment confirmed by EHF-PTA $(0.5-20 \mathrm{kHz})$. However, a direct comparison between that study and the present study is difficult because they used another criterion to define a "reduction" in DP-OAE. In a study of 21 children receiving cisplatin, EHF-PTA detected changes earlier than DP-OAE in nine patients, whereas an early change was detected by DP-OAE in only one patient. ${ }^{15)}$ In contrast, in the present study, DP-OAE detected a change in one ear earlier than EHF-PTA. The difficulty in measuring DP-OAE above $8 \mathrm{kHz}$ seems to reduce its sensitivity in detecting ototoxicity. Nevertheless, DP-OAE is a potentially useful tool for monitoring child patients or handicapped people who cannot be evaluated with PTA. DP-OAE could also be used as an accessory tool to support the results of EHF-PTA.

Cisplatin can cause both ototoxicity and nephrotoxicity. The protein, kidney injury molecule 1 , which is induced in the renal proximal tubular epithelium after cisplatin therapy, can also be expressed in the cochlea, and caused ototoxic effects in an animal study. ${ }^{23)}$ Reports of the incidence of cisplatin-induced nephrotoxicity are relatively rare. An increase in the serum $\mathrm{Cr}$ concentration has been reported in $41 \%$ of patients treated with high doses of cisplatin $\left(70-85 \mathrm{mg} / \mathrm{m}^{2}\right.$ for each cycle, 5.3 mean cycles). ${ }^{24)}$ And Máthé, et al. ${ }^{25)}$ reported that 23 of 38 patients with lung cancer showed pathological increases in serum $\mathrm{Cr}$ after $2-4$ cisplatin infusions $\left(75 \mathrm{mg} / \mathrm{m}^{2}\right)$ per cycle. From our result, we infer that the incidence of cisplatin-induced nephrotoxicity $(10 \%)$ is lower than the incidence of ototoxicity $(40 \%)$. However, close monitoring must be mandatory for nephrotoxicity, because its consequences are lethal.

The purpose of monitoring ototoxicity during cisplatin chemotherapy is the early detection of sensorineural hearing impairment before the patient is him/herself aware of it. If serious ototoxicity is detected, an alternative, less ototoxic drug, such as carboplatin, could be considered before ototoxicity progresses. The timing of the interruption of cisplatin should be considered based on various factors, including the amount of hearing deterioration, the hearing level before chemotherapy, the pathological type or grade of cancer, and the patient's age. However, to the best of our knowledge, there is no specific criterion for the discontinuation of cisplatin therapy. The critical dose of Cis-OT is still controversial. The average cumulative dose of cisplatin to cause a threshold change in EHF-PTA was reported to be 400 or $343.6 \mathrm{mg} / \mathrm{m}^{2}$ in two different studies. ${ }^{18,26)}$ In one study using DP-OAE, the SNR amplitude decreased significantly when the patients received a cumulative dose of more than $200 \mathrm{mg} / \mathrm{m}^{2}$. $)$ In the present study, ototoxicity was detected with EHF-PTA and DP-OAE after a total cumulative dose of $780 \mathrm{mg} / \mathrm{m}^{2}$ in two subjects. Another subject displayed ototoxicity at a total cumulative dose of $480 \mathrm{mg} / \mathrm{m}^{2}$ and another at $240 \mathrm{mg} / \mathrm{m}^{2}$. The average cumulative dose of cisplatin during which ototoxicity developed was $570 \pm 261.53$ $\mathrm{mg} / \mathrm{m}^{2}$. However, three subjects who received a cumulative cisplatin dose $>700 \mathrm{mg} / \mathrm{m}^{2}$ showed no change on either EHFPTA or DP-OAE, implying that individual variability, such as genetic factors, affect the development of ototoxicity. In this study, there was no significant correlation between the cumulative dose of cisplatin and the presence of hearing threshold changes, which could be attributable to the small sample size. The four patients with HL after treatment showed threshold changes below $8 \mathrm{kHz}$, but none of them was aware of their hearing impairment during or after chemotherapy. This result justifies the monitoring of ototoxicity.

The limitation of this study was its small sample size. Only 10 patients completed all the scheduled follow-up evaluations. Because of the severity of the patients' existing disease, some died during the research period, and some showed very poor compliance with the hearing test. Patients who did not feel their hearing was impaired tended to ignore the importance of the follow-up hearing tests. For this reason, seven patients discontinued regular hearing tests during and after their treatment with cisplatin. For the future, the study with larger 
sample size will be necessary to clarify the effectiveness of EHF-PTA and DP-OAE for monitoring cisplatin-induced ototoxicity. Several investigators argued that both EHF-PTA and OAE are problematic in patients with HL, particularly in the elderly, because of the limited responses to test due to pre-existing losses of outer hair cells in the cochlear basal region. ${ }^{27-30)}$ For the cases of elderly patients, the baseline testing prior to ototoxic drug administration will be mandatory for the precise interpretation using "change of value". Ress, et al. ${ }^{17)}$ studied a greater number of patients including elderly subjects and DPOAE showed effective sensitivity to detect ototoxicity. In the present study, all subjects performed EHF-PTA and DP-OAE before initial cisplatin infusion and the "change of value" after treatment were calculated.

As mentioned several times before, HL can occur without any subjective otological symptoms. It is also easy for oncologists to overlook the monitoring of hearing, because they consider the cancer therapy to be the most important issue. Detailed information about cisplatin-induced ototoxicity should be offered to patients and otologists should be involved in establishing a well-organized protocol for hearing tests for all cisplatintreated patients.

\section{Conclusion}

In our study, the incidence rate of Cis-OT was $40 \%$ (four of 10 patients) when detected with either EHF-PTA or DP-OAE. Although both EHF-PTA and DP-OAE showed the same sensitivity in detecting ototoxicity, they did not produce coincident results in all cases. The two hearing tests complement one another, and clinicians should use both tests simultaneously in every cycle of chemotherapy to ensure the detection of ototoxicity. Cisplatin may induce nephrotoxicity less frequently than it induces ototoxicity.

\section{Acknowledgments}

This study was supported by Dong-A ST Co., Ltd, South Korea.

Cisplatin administered in this study was not related with Dong-A ST Co., Ltd.

\section{REFERENCES}

1) Yilmaz S, Oktem F, Karaman E. Detection of cisplatin-induced ototoxicity with transient evoked otoacoustic emission test before pure tone audiometer. Eur Arch Otorhinolaryngol 2010;267:1041-4.

2) Lanvers-Kaminsky C, Krefeld B, Dinnesen AG, Deuster D, Seifert E, Würthwein G, et al. Continuous or repeated prolonged cisplatin infusions in children: a prospective study on ototoxicity, platinum concentrations, and standard serum parameters. Pediatr Blood Cancer 2006;47:183-93.

3) Schaefer SD, Post JD, Close LG, Wright CG. Ototoxicity of low- and moderate-dose cisplatin. Cancer 1985;56:1934-9.

4) American Speech-Language-Hearing Association. Guidelines for the audiologic management of individuals receiving cochleotoxic drug therapy. ASHA 1994;36:11-9.

5) Beattie RC, Kenworthy OT, Luna CA. Immediate and short-term reliability of distortion-product otoacoustic emissions. Int J Audiol 2003;42:348-54.

6) Eiamprapai P, Yamamoto N, Hiraumi H, Ogino-Nishimura E, Kitamura M, Hirano S, et al. Effect of cisplatin on distortion product otoacoustic emissions in Japanese patients. Laryngoscope 2012;122: 1392-6.

7) Komune S, Asakuma S, Snow JB Jr. Pathophysiology of the ototoxicity of cis-diamminedichloroplatinum. Otolaryngol Head Neck Surg 1981;89:275-82.

8) Brummett RE. Drug-induced ototoxicity. Drugs 1980;19:412-28.

9) Nakai Y, Konishi K, Chang KC, Ohashi K, Morisaki N, Minowa Y, et al. Ototoxicity of the anticancer drug cisplatin. An experimental study. Acta Otolaryngol 1982;93:227-32.

10) Konishi T, Gupta BN, Prazma J. Ototoxicity of cis-dichlorodiammine platinum (II) in guinea pigs. Am J Otolaryngol 1983;4:18-26.

11) Schweitzer VG, Hawkins JE, Lilly DJ, Litterst CJ, Abrams G, Davis JA, et al. Ototoxic and nephrotoxic effects of combined treatment with cis-diamminedichloroplatinum and kanamycin in the guinea pig. Otolaryngol Head Neck Surg 1984;92:38-49.

12) Arenberg IK. Dizziness and Balance Disorders. New York: Kugler Publications; 1993.

13) Coradini PP, Cigana L, Selistre SG, Rosito LS, Brunetto AL. Ototoxicity from cisplatin therapy in childhood cancer. J Pediatr Hematol Oncol 2007;29:355-60.

14) Fausti SA, Larson VD, Noffsinger D, Wilson RH, Phillips DS, Fowler CG. High-frequency audiometric monitoring strategies for early detection of ototoxicity. Ear Hear 1994;15:232-9.

15) Knight KR, Kraemer DF, Winter C, Neuwelt EA. Early changes in auditory function as a result of platinum chemotherapy: use of extended high-frequency audiometry and evoked distortion product otoacoustic emissions. J Clin Oncol 2007;25:1190-5.

16) Littman TA, Magruder A, Strother DR. Monitoring and predicting ototoxic damage using distortion-product otoacoustic emissions: pediatric case study. J Am Acad Audiol 1998;9:257-62.

17) Ress BD, Sridhar KS, Balkany TJ, Waxman GM, Stagner BB, Lonsbury-Martin BL. Effects of cis-platinum chemotherapy on otoacoustic emissions: the development of an objective screening protocol. Third place--Resident Clinical Science Award 1998. Otolaryngol Head Neck Surg 1999;121:693-701.

18) Stavroulaki P, Apostolopoulos N, Segas J, Tsakanikos M, Adamopoulos G. Evoked otoacoustic emissions--an approach for monitoring cisplatin induced ototoxicity in children. Int J Pediatr Otorhinolaryngol 2001;59:47-57.

19) Delehaye E, Capobianco S, Bertetto IB, Meloni F. Distortion-product otoacoustic emission: early detection in deferoxamine induced ototoxicity. Auris Nasus Larynx 2008;35:198-202.

20) Dhooge I, Dhooge C, Geukens S, De Clerck B, De Vel E, Vinck BM. Distortion product otoacoustic emissions: an objective technique for the screening of hearing loss in children treated with platin derivatives. Int J Audiol 2006;45:337-43.

21) Sakamoto M, Kaga K, Kamio T. Extended high-frequency ototoxicity induced by the first administration of cisplatin. Otolaryngol Head Neck Surg 2000;122:828-33.

22) Reavis KM, Phillips DS, Fausti SA, Gordon JS, Helt WJ, Wilmington $\mathrm{D}$, et al. Factors affecting sensitivity of distortion-product otoacoustic emissions to ototoxic hearing loss. Ear Hear 2008;29:875-93.

23) Mukherjea D, Whitworth CA, Nandish S, Dunaway GA, Rybak LP, Ramkumar V. Expression of the kidney injury molecule 1 in the rat cochlea and induction by cisplatin. Neuroscience 2006;139:733-40.

24) de Jongh FE, van Veen RN, Veltman SJ, de Wit R, van der Burg ME, van den Bent MJ, et al. Weekly high-dose cisplatin is a feasible treatment option: analysis on prognostic factors for toxicity in $400 \mathrm{pa}-$ tients. Br J Cancer 2003;88:1199-206. 
25) Máthé C, Bohács A, Duffek L, Lukácsovits J, Komlosi ZI, Szondy K, et al. Cisplatin nephrotoxicity aggravated by cardiovascular disease and diabetes in lung cancer patients. Eur Respir J 2011;37:888-94.

26) Biro K, Noszek L, Prekopp P, Nagyiványi K, Géczi L, Gaudi I, et al. Characteristics and risk factors of cisplatin-induced ototoxicity in testicular cancer patients detected by distortion product otoacoustic emission. Oncology 2006;70:177-84.

27) Osterhammel D. High frequency audiometry. Clinical aspects. Scand Audiol 1980;9:249-56.
28) Kujansuu E, Rahko T, Punnonen R, Karma P. Evaluation of the hearing loss associated with cis-platinum treatment by high-frequency audiometry. Gynecol Oncol 1989;33:321-2.

29) Lonsbury-Martin BL, Cutler WM, Martin GK. Evidence for the influence of aging on distortion-product otoacoustic emissions in humans. J Acoust Soc Am 1991;89(4 Pt 1):1749-59.

30) Stover L, Norton SJ. The effects of aging on otoacoustic emissions. J Acoust Soc Am 1993;94:2670-81. 